\title{
Marta em notícia: a (in)visibilidade do futebol feminino no Brasil
}

\author{
Marta news: (in)visibility of women's football in Brazil
}

\author{
Soraya Barreto Januário \\ Universidade Federal de Pernambuco (UFPE), Recife / Brasil \\ Doutora em Ciências da Comunicação pela Universidade Nova de Lisboa \\ sorayabarretopp@gmail.com
}

\begin{abstract}
RESUMO: O presente artigo visa analisar a cobertura realizada pelos portais de notícias pernambucanos sobre a Copa do Mundo de Futebol Feminino 2015 e, especialmente, sobre a jogadora Marta. Utilizamos como aporte teórico os estudos sobre futebol à luz das teorias de Gastaldo (2005) e Helal (2003) e dos estudos de gênero como Beauvoir (1980) e Goellner (2005). A metodologia proposta foi o estudo de caso descritivo e interpretativo, por meio da análise qualitativa dos discursos e espaços ocupados pelo campeonato mediante o monitoramento da mídia. Como resultados, emergiram padrões de representação e discursos dominantes.
\end{abstract}

Palavras-chave: Futebol; Copa do Mundo; Mulheres; Economia Política da Comunicação; Gênero.

ABSTRACT: This article aims to analyze the coverage held by the news portals of Brazil about the FIFA Women's World Cup 2015, and specially, about the soccer player Marta. To carry out the research, we used as theoretical support the Football Studies in the light of the theories of Gastaldo (2005), Helal (2003) and Gender Studies with Beauvoir (1980) and Goellner (2005). The proposed methodology was a study of descriptive and interpretive case, through the qualitative analysis of the discourses and spaces occupied by championship through media monitoring. As a result, emerging patterns of representation and dominant discourses.

KEYWORDS: Football; World Cup; Women; Political Economy of Communication; Gender. 


\section{INTRODUÇÃo}

O sociólogo Marcel Mauss (2003), ao debater o simbolismo e as relações sociais, advogou que a lógica mercantil moderna não substituiu as formas antigas de constituição de vínculos entre os atores sociais e relatou que tais formas continuam presentes nas sociedades modernas. Mauss defendeu a existência de um fato social total que se revela a partir de duas compreensões de totalidade: a primeira baseada em um fenômeno complexo pelo qual estruturas sociais, tais como a família, a política, a educação, a religião, dentre outros, se manifestam e, portanto, mobilizam a sociedade e as suas instituições sociais em prol de um mesmo objetivo; a segunda, também no sentido de totalidade, de que a natureza desses bens produzidos pelas comunidades não é apenas material, mas também e, sobretudo, de natureza simbólica.

O esporte - e, particularmente, o futebol - parece ilustrar bem o conceito cunhado por Mauss, por meio das amarras sociais que o perpassam e o suportam, pelo seu caráter coletivo, social e popular. Nesse sentido, esse esporte pode ser percebido hoje como um dos grandes fenômenos socioculturais do século XXI, pois é capaz de influenciar diversos segmentos da sociedade - do cultural ao econômico - se pensarmos em sua imensa capacidade de fomentar consumo. Com efeito, abarca uma gama de elementos subjetivos nas pessoas, tais como: paixão, emoção, medo, frustração etc. Tais características subjetivas impõem ao tema futebol uma difícil tarefa de análise e mensuração fiel.

0 futebol foi naturalizado em estruturas associadas à construção da masculinidade e da virilidade (Januário, 2015). A própria designação de futebol feminino se torna excludente ao determinar a necessidade de especificar apenas quando o desporto é praticado por mulheres, o que confere um significado universal, mais uma vez, ao masculino em detrimento do feminino.

As masculinidades e as feminilidades são construídas simultaneamente em dois campos relativos às relações de poder: nas relações de homem com mulheres (desigualdade de gênero) e também nas relações dos homens com outros homens (desigualdades baseadas em raça, etnicidade, sexualidade). E, por esses fatores, as características impostas ao feminino estiveram tão distantes de arenas esportivas 
como a do futebol. Delimitar certos ambientes como impróprios para as mulheres é um claro mecanismo de disciplina, coerção e poder.

Diante do exposto, pretende-se, nesse artigo, analisar a cobertura midiática realizada pelos portais de notícia pernambucanos sobre a Copa do Mundo de Futebol Feminino de 2015, que decorreu no Canadá, entre 06 de junho a 05 de julho do referente ano, e foi transmitida pela TV Brasil (Canal Aberto). A sétima edição do evento teve alteração no número de países participantes, com a expansão de 16 para 24 seleções, aumentando o número de jogos de 32 para 52 no total. Apesar do aumento do número de países participantes, o torneio não ganhou a visibilidade que merece. Além disso, foi palco de algumas polêmicas, como o uso de gramado artificial, o que dificulta o jogo e machuca as jogadoras. Vale ressaltar que todos os jogos dos campeonatos masculinos são realizados em gramado natural. Sobre essa polêmica, reportagem do site Lancenet publicou:

\begin{abstract}
Gramado artificial dos estádios do Canadá foi aceito pela Fifa, mesmo sob protesto de atletas. Jogadoras correm maior risco de lesão, e futebol tem qualidade prejudicada. Enquanto na Copa do Mundo masculina de futebol é regra todos os gramados serem naturais, o Mundial feminino não ganha tal atenção por parte da Fifa. Sob protesto de jogadoras, a grama artificial dos estádios canadenses foi aprovada pela entidade suíça. Lá se foi a primeira fase do torneio, e as críticas por parte das atletas não diminuíram. ${ }^{1}$
\end{abstract}

Apesar dos inúmeros apelos realizados por Marta, Cristiane e Formiga jogadoras de destaque da seleção nacional -, a FIFA aprovou a realização do campeonato em grama sintética que, para além de prejudicar a performance da bola, o atrito em quedas pode causar ferimentos e queimaduras nas atletas.

No tocante ao corpus analisado para o presente artigo, foram selecionadas as notícias veiculadas pelos portais do Globo Esporte, torcedores.com, SportTV, ESPN e Esportes Uol, com o intuito de saber qual a visibilidade alcançada pelo certame e o comportamento da cobertura realizada por esses canais. É pertinente ressaltar que tal pesquisa decorreu no âmbito dos estudos realizados pelo OBMÍDIA - Observatório de Mídia da UFPE, que monitora e analisa o comportamento da mídia.

\footnotetext{
${ }^{1}$ LANCENET, 19/06/15.
} 


\section{FUTEBOL, ESPORTE PARA MENINAS?}

Desde sua implementação nos gramados, o futebol tem sido um jogo praticado majoritariamente por homens e, portanto, vem sendo agregado na cultura como um interesse masculino "obrigatório" (Louro, 1995). No entanto, inicialmente o futebol foi entendido como um esporte de elites, que homens brancos e abastados praticavam. Apenas quando o futebol começou a fazer parte do cotidiano da população negra e classes populares, a presença feminina foi descartada com a justificativa de que "filhas de boa família não devem se misturar com jogadores de futebol”. ${ }^{2}$

Nessa perspectiva, a mulher foi sendo excluída dos espaços esportivos e de suas práticas. Cabe ainda ressaltar que a inserção da mulher em certos esportes, compreendidos como "de contato" possui um longínquo histórico de restrições e proibições. Desde os primórdios da história do esporte e do movimento olímpico, as mulheres eram proibidas de participar e, portanto, cabia-lhes apenas a entrega dos prêmios aos vencedores. Esse ato de entrega das premiações se estende até hoje com belos corpos objetificados como parte do prêmio (Januário, 2013). Esse pensamento iniciou seu processo de mudança no Brasil nas décadas de 80 e 90, havendo maior incentivo para esportes com maior contato físico, como judô, basquete e, claro, o futebol (Goellner, 2005).

0 futebol foi naturalizado em estruturas associadas à construção da masculinidade e da virilidade (Januário, 2015). A própria designação de futebol feminino se torna excludente ao determinar a necessidade de especificar apenas quando o desporto é praticado por mulheres, o que confere um significado universal, mais uma vez, ao masculino, em detrimento do feminino.

Para Edison Gastaldo “a Copa do Mundo é um fato social de enorme importância na cultura brasileira contemporânea, e cujo acesso está estreitamente vinculado a seu caráter mediatizado". ${ }^{3}$ Entretanto, é importante apontar que o campeonato comentado pelo antropólogo se refere à prática masculina, visto a notória invisibilidade da competição feminina. Dessa forma, é pertinente compreender como

\footnotetext{
${ }^{2}$ WITTER. O que é futebol, p. 58.

${ }^{3}$ GASTALDO. Uma arquibancada eletrônica, p. 362.
} 
se constroem esses distanciamentos e as relações de poder em diversas esferas sociais, dentre elas, o futebol enquanto fenômeno social.

Desde as célebres palavras de Beauvoir (1980) "não se nasce mulher, tornase", entendeu-se que o gênero seria um processo ambíguo de autoconstrução, onde a distinção entre sexo e gênero converte-se no "variado modo de aculturação corpórea, para além de um destino crivado na anatomia". ${ }^{4}$ Para Butler, na assertiva de Beauvoir reconhece-se que, para se assumir as características de gênero, há que se submeter a uma condição cultural, que incita a participação no ato de criação dessa mesma condição. Nessa perspectiva, a afirmação de Beauvoir considera o compromisso e o envolvimento nos moldes existenciais, que se assegura por um movimento dialético, isto é, como algo que sofre influência da cultura, mas que também a impõe suas determinações.

No Brasil, até a chamada Belle-Époque, período compreendido entre o final do século XIX e início do século XX, os homens e mulheres da aristocracia tinham seus papeis e espaços estritamente delimitados entre o privado e o público, distinções essas que ganham destaque nas discussões do feminismo liberal.

Com alguma frequência, os termos público e privado são utilizados sem preocupação com sua prévia definição e clareza de contexto, como se todos compreendessem o seu significado independentemente do contexto em que os empregam. Entretanto, os estudos feministas têm colocado tais preocupações na centralidade de seus debates e questionado suas aplicações quando trazem à tona duas utilizações principais. Segundo Okin (2008), a primeira refere-se à distinção entre Estado e sociedade - tal como propriedade pública versus privada; enquanto isso, a segunda diz respeito à distinção entre vida não doméstica e vida doméstica. A diferença entre estes dois usos, aponta Okin, ${ }^{5}$ consiste no fato de a sociedade civil (Hegel apud Engels), na primeira dicotomia, ser entendida como pertencente ao privado e, na segunda, como integrante do mundo público.

Wendy Weinstein (apud Okin, 2008) desenvolveu uma analogia entre o conceito de público/privado e as camadas de uma cebola: segundo ele, esses estão um para o outro tal como em uma cebola - uma camada se sobrepõe a outra, que,

\footnotetext{
${ }^{4}$ BUTLER. Variações sobre sexo e gênero: Beauvoir, Witting e Foucault, p. 35.

${ }^{5}$ OKIN. Gênero, o público e o privado, p. 307.
} 
por sua vez, estará dentro de outra camada e assim sucessivamente. E explica o fato de algo, tido como público em relação a uma determinada esfera poder ser considerado privado em relação a uma outra. Existem, assim, múltiplos significados e não o dualismo associado ao conceito. Nesse sentido, dá-se lugar às dicotomias de Estado/sociedade e não-doméstico/doméstico. ${ }^{6}$ Nessa perspectiva, Okin optou por utilizar a segunda separação, público-doméstico, já que acreditava que é a permanência desta dicotomia que torna possível aos teóricos ignorarem a natureza política da família e a relevância da justiça na vida pessoal e, por conseguinte, grande parte das desigualdades de gênero.

Para as feministas liberais, a distinção existente entre público e doméstico é ideológica no sentido em que apresenta a sociedade a partir de uma perspectiva masculina e patriarcal, baseada em pressupostos sobre diferentes naturezas e papéis sociais de homens e mulheres. As investigadoras feministas têm argumentado que a divisão doméstica do trabalho e, especialmente, a prevalência da mulher na criação dos filhos, são socialmente construídas, e, portanto, são questões de relevância política.

É pertinente destacar que os domínios da vida doméstica e não-doméstica, econômica e política não podem ser interpretados isolados um do outro. Nesse âmbito, torna-se pertinente discutir as relações de tais conceitos com a economia política e como eles perpassam a comunicação na tentativa de compreender como se dá a (in)visibilidade das mulheres no campo dos esportes, do futebol e da mídia.

\section{A COBERTURA DA COPA DO MUNDO DE FUTEBOL FEMININO: O QUE DIZEM OS PORTAIS DE NOTÍ́cias?}

0 recorte metodológico utilizado foi o estudo de caso descritivo e interpretativo, de ordem qualitativa. A realização de um estudo de caso descritivo e interpretativo nos levou a desvelar como se deu a cobertura do Campeonato Mundial de Futebol Feminino em 2015 quando da interpretação dos dados coletados. Ao compreendermos que o estudo de caso possibilita a compreensão de fenômenos

\footnotetext{
${ }^{6}$ OKIN. Gênero, o público e o privado, p. 307.
} 
individuais, sociais e políticos, "estudo de caso permite uma investigação para preservar as características holísticas e significativas dos eventos da vida real". ${ }^{7}$

Segundo Robert Stake (2000), a investigação precisa considerar alguns aspectos, tais como: a natureza e histórico do caso; o contexto (físico, econômico, político, estético etc.); outros casos pelos quais é reconhecido; os informantes pelos quais pode ser conhecido. Todas essas características têm forte relação com a natureza da observação empreendida nesse artigo, diante da alta quantidade de material analisado - corpus composto por cinco portais de notícias com monitoramento diário durante 30 dias.

O quadro teórico-metodológico dos Estudos de Gênero é um importante recurso quando da análise acerca da cobertura sobre o evento nos portais de notícias dos principais grupos de mídia esportivos brasileiros, entre 06 de junho e 05 de julho de 2015, por revelar tendências investigativas em torno da presença das mulheres nas notícias.

\begin{tabular}{|l|l|}
\hline \multicolumn{1}{|c|}{ PORTAL ESTUDADO } & \multicolumn{1}{c|}{ GRUPO A QUE PERTENCE } \\
\hline Globoesporte.com & $\begin{array}{l}\text { É um site de esportes do Grupo Globo e realiza a convergência entre } \\
\text { os programas esportivos da Rede Globo: Globo Esporte, Auto } \\
\text { Esporte e Esporte Espetacular. Lançado em 2005 como Esporte na } \\
\text { Globo, em 2006 passou a ter o nome atual. Em 2007, assumiu a } \\
\text { liderança na audiência do mercado de esportes na internet } \\
\text { brasileira. Por ser um site de cobertura nacional, as notícias sobre } \\
\text { esportes produzidas no âmbito local e as que abordam questões } \\
\text { relacionadas a Pernambuco são veiculadas nele. O portal também } \\
\text { insere conteúdo do canal de esportes da Globosat, o SporTV. }\end{array}$ \\
\hline SportTV & $\begin{array}{l}\text { É um site de esportes do Grupo Globo e insere conteúdo do canal de } \\
\text { esportes da Globosat, um dos canais fechado do grupo. }\end{array}$ \\
\hline Esporte Uol & $\begin{array}{l}\text { Canal do portal UOL que trata das notícias esportivas do Brasil e do } \\
\text { Mundo. }\end{array}$ \\
\hline Torcedores.com & $\begin{array}{l}\text { Canal de esportes de conteúdo colaborativo e não pertence a um } \\
\text { grande grupo midiático. Com mais de 500 colaboradores do Brasil } \\
\text { inteiro. }\end{array}$ \\
\hline ESPN & $\begin{array}{l}\text { É uma rede de TV por assinatura dos Estados Unidos dedicada à } \\
\text { transmissão e produção de programas esportivos 24 horas por dia. } \\
\text { A versão brasileira está associada ao portal Uol. }\end{array}$ \\
\hline
\end{tabular}

Tabela 1. Caracterização dos portais de notícias analisados nesse estudo.

\footnotetext{
${ }^{7}$ YIN. Estudo de caso, p. 21.
} 
A pesquisa se deu através de palavras-chave mais específicas - como "mundial de futebol feminino" e "Marta" (nosso objeto de pesquisa) - até palavras mais genéricas e que abrangeram a possibilidade de encontrarmos novas matérias em portais que dão menos visibilidade ao tema - como "futebol feminino" e "Copa do Mundo". A partir do colhimento e análise das matérias encontradas nos principais portais, foram determinadas categorias para a representação dessas matérias.

É pertinente ressaltar que a internet figura entre os diversos meios de comunicação de massa que dialogam com o fenômeno esportivo. 0 seu crescimento exponencial decorre da democratização e, consequentemente, do aumento no acesso à tecnologia, que permitem a conexão com o mundo virtual de qualquer lugar e a qualquer hora.

A última Copa do Mundo de futebol feminino de 2015 ocorreu no Canadá, no período de 06 de junho a 05 de julho. E, mais uma vez, a seleção brasileira estava representada por uma equipe que, apesar de poucos recursos, mantém um bom reconhecimento no meio esportivo feminino devido a atletas como Cristiane, Formiga e Marta; além de conquistas importantes, como medalha de prata duas vezes nas Olimpíadas. Mas o cenário da seleção feminina dentro do próprio país é diferente, não há um reconhecimento expressivo da mídia, da sociedade e muito menos da CBF, o que influencia diretamente na falta de investimentos e apoio ao futebol feminino. Certamente, a cultura do machismo e o histórico de proibições e assertivas sociais que argumenta que "futebol não é coisa de mulher", relacionando apenas a práticas masculinas, nos faz perceber que, mesmo uma sendo atleta de alta performance, isso não é o suficiente para uma mulher provar a sua capacidade e obter reconhecimento. Um exemplo disso é o caso da atacante Marta, camisa 10 da seleção brasileira, cinco vezes eleita a melhor do mundo pela FIFA, artilheira do Mundial Feminino com 15 gols, maior artilheira da seleção brasileira (masculina e feminina) com 100 gols e ídola no meio futebolístico. Apesar de todo o foco relacionado ao futebol feminino ser em torno dela, a jogadora não chega nem perto de ter o reconhecimento e apoio de um jogador em ascensão no futebol masculino. Essa se configura em uma das principais motivações para a confecção do presente artigo. Abordar a exposição de Marta diante da mídia e de que forma ela foi citada nas matérias durante a Copa do Mundo de 2015 são os objetivos desse trabalho. 
A partir do colhimento e análise das matérias encontradas nos portais de notícias esportivas no âmbito nacional selecionados e, portanto, foram determinadas categorias para a representação dessas matérias.

As categorias foram escolhidas de acordo com a frequência, o grau de importância e tipos de referência à jogadora Marta. São elas:

1. Notícia Padrão: Breve comentário sobre a partida, seus principais lances e resultados;

2. "Brasil de Marta": Matérias que frequentemente usam o nome de Marta para fazer referência à seleção brasileira;

3. Destaque Marta: Matérias que dão destaque a algum comportamento da jogadora, seja do seu dia a dia ou dos recordes que atinge;

4. Crítica: Matérias que destacam o não apoio ao futebol feminino e o pouco destaque concentrado em uma única jogadora;

5. Outras: Matérias que citam jogos ou acontecimentos que não são relacionados diretamente com a jogadora.

\section{NotícIa PADRÃo}

Segundo Wolf (2003) “[...] a noticiabilidade corresponde ao conjunto de critérios, operações e instrumentos com os quais os órgãos de informação enfrentam a tarefa de escolher, quotidianamente, de entre um número imprevisível e indefinido de fatos". ${ }^{8}$ Nessa categoria, prevalecem os comentários mais técnicos sobre os lances de uma partida, apostas para os próximos jogos e situação da tabela/colocação na tabela de jogos. Desse modo, pudemos observar o nome de Marta sendo citado ao lado dos nomes de outras veteranas da equipe, como Formiga e Cristiane, e/ou seu nome sendo citado apenas para registrar algum lance que a jogadora realizou/participou, algum gol feito, assistência etc. Não há, de forma geral, um destaque à jogadora ou a qualquer outra. É seguida uma linha padrão de apresentação das informações sobre o campeonato como em qualquer outro.

\footnotetext{
${ }^{8}$ WOLF. The beauty myth, p. 190.
} 


\section{“BRASIL DE MARTA"}

Nesse caso, a matéria muda de direção. É possível perceber que, apesar de muitas das notícias continuarem falando sobre os jogos, algum lance específico, curiosidades sobre a Copa do Mundo; elas usam o nome de Marta para identificar a Seleção Brasileira. Termos como "Brasil de Marta", "Marta e Cia.", "Seleção de Marta" etc. são usados constantemente como sinônimo de Brasil, conforme essa manchete do Brasil Post: "Marta e as meninas da Seleção vão precisar da sua torcida para bater a Austrália" (21 de Junho de 2015). Até em casos de reportagens que abordam o jogo ou a situação de outra seleção, quando é necessário citar o Brasil como referência ou exemplo de algo, os termos usados serão os que usam Marta como representante. Esse processo é resultante do desempenho da jogadora em campo e sua visibilidade devido aos prêmios que conquistou. 0 processo de escolha da notícia, usando Marta como destaque, transforma os acontecimentos, que são a matéria prima da informação, num produto - e Marta tem sido o principal "produto" que representa o futebol feminino brasileiro.

Portanto, se faz necessário compreender que a dependência da jogadora Marta na seleção brasileira e a cobrança pelo seu bom desempenho tem grande influência no tratamento que a mídia faz da sua imagem.

\section{Destaque Marta}

Diferentemente da categoria anterior, que usa a imagem de Marta, mas versa sobre a seleção de futebol feminino como foco, as matérias que se encaixam na categoria "Destaque Marta" ficam responsáveis por retratar de forma positiva a jogadora em si. São assuntos relacionados aos seus recordes, a tietagem dos fãs e ao seu dia a dia de treinos intensos. Em nenhum momento, Marta é vista como super celebridade, diferentemente dos jogadores do futebol masculino, é apenas uma atleta de alta performance admirada. Isto é, Marta não deve ser percebida como uma "jogadora-celebridade" (Taylor, 2001). Em meio aos critérios para a consagração do que se entende por celebridade, Kellner (2004) advoga que "para se tornar uma celebridade é preciso ser reconhecida como uma estrela no campo 
do espetáculo, seja no esporte, no entretenimento, ou na política" ${ }^{9}$ Nesse sentido, alie-se os altos índices de audiência e uma identificação/inspiração com os espectadores, Marta pode ser percebida como uma personalidade desse universo imaginário dos espectadores da crescente indústria do entretenimento e do esporte. Contudo, o protagonismo de Marta, diferente de supercelebridades como Neymar, é tímido e pontual pelo uso seletivo de sua imagem nos meios de comunicação apenas em períodos óbvios de visibilidade - como Copa do Mundo, Olimpíadas etc. - e também pelo diminuto interesse de patrocinadores. A imagem da jogadora se mantém no segmento esportivo, mais uma vez, diferentemente, dos atletas do futebol masculino. É pertinente pontuar que é constante a elocução de uma narrativa midiática que apresenta certos personagens do esporte como capazes de ofertar elementos e sentidos desencadeadores de constructos comportamentais, ideológicos e imagéticos como elementos de aspiração e inspiração para a juventude. E, por isso mesmo, notamos a constante invisibilidade desse caráter aspiracional e simbólico da figura da Marta quando muitas das matérias "precisam" citar nomes de jogadores do futebol masculino para critério de comparação. Numa reportagem do Globo Esporte, cita-se Klose e Ronaldo: "Quinze gols em Copas, cinco vezes melhor do mundo: prazer, Marta" (12 de Junho de 2015). Quando são ligadas à expectativa do jogo, as notícias trazem depoimentos de Marta e falam dos seus treinos físicos para se preparar para os jogos. A atleta acaba por ser tratada apenas de forma profissional, já que não há grande referência à sua vida fora do futebol. Isso pode ser explicado com motivos como: a própria atleta não se expõe enquanto celebridade, polêmicas, festas e relacionamentos famosos; mas, por outro lado, nos parece sugerir que não há um interesse midiático devido à invisibilidade da própria modalidade esportiva com atletas mulheres; e, ainda, Marta não é considerada pela mídia e sociedade um ícone de beleza (Wolf, 2009), como acontece com a tenista Sharapova, por exemplo.

\footnotetext{
${ }^{9}$ KELLNER. Cultura da mídia, p. 6.
} 


\section{CríticA}

Nessa categoria, encontramos matérias que parecem aproveitar a visibilidade da Copa do Mundo para opinar e denunciar a realidade do futebol feminino no Brasil, utilizando a imagem de Marta como exemplo e, muitas vezes, como porta-voz dessas críticas. É sabido que a camisa 10 da seleção sempre se posiciona na mídia em relação às más condições da prática do futebol feminino no país, o não apoio da própria CBF e também da FIFA são corriqueiramente citados pela atleta. No Brasil, aparentemente o descaso da mídia e a falta de patrocínios. “O preconceito é definitivamente uma das razões que fazem o futebol feminino avançar lentamente no Brasil" (09 de Junho de 2015), disse Marta em entrevista para a FourFourTwo, citada na matéria do Torcedores.com. Além da crítica em torno do preconceito com prática do futebol pela mulher, a situação ainda se agrava quando a única representante do país que a mídia reconhece é Marta e, para finalizar, quando as atletas estão ganhando muito menos do que os homens ("Melhor jogadora do mundo, Marta não chegou aos milhões do futebol" Infomoney - 09 de Junho de 2015). As emissoras de televisão e mídia de massa são recorrentemente alvo de críticas devido ao silenciamento e invisibilidade dada à modalidade feminina. Prova disso é a transmissão do campeonato que foi realizada pela TV Brasil de cunho federal e pública. Emissoras abertas e fechadas, privadas (apesar da concessão pública), não transmitiram a primeira fase da Copa ("Band Termina Primeira Fase Da Copa Do Mundo Feminina Sem Mostrar O Brasil” Torcedores.com - 18 de Junho de 2015), como também preferiram colocar na programação jogos do futebol masculino russo.

\section{OUTRAS}

Diferentes notícias durante a Copa do Mundo citaram a jogadora Marta. Sua opinião - mesmo em jogos que não participaria - como figura de influência e porta voz da seleção nacional. Não há representatividade de outras jogadoras, apenas o discurso do técnico Vadão. Como nas manchetes do Globo Esporte: "Fora do Pan, Marta pede continuidade e atenção à nova geração da Seleção" (23 de Junho de 
2016) e "Vadão inocenta goleira e indica que vai manter base da Seleção para o Pan" (23 de Junho 2015).

\section{CONSIDERAÇõES FINAIS}

A mídia e o jornalismo, enquanto instância social e processo pedagógico cultural (Louro, 1995) que pode tanto valorizar e legitimar conteúdos, grupos e sujeitos sociais quanto silenciá-los, deve perceber a importância de seu papel na configuração de valores sociais mais plurais em detrimento de um ideal hegemônico.

A presente pesquisa e análise das notícias que circularam pelos portais durante a Copa do Mundo de 2015 nos permitiram sugerir alguns discursos dominantes sobre a representação do futebol feminino no Brasil e da própria Marta são vistas. 0 processo de construção dos discursos midiáticos são mediados no social onde se repercute, interesses, lógicas e relações de poder. A construção de sentidos sobre esses discursos e as relações de gênero na sociedade contemporânea, por parte das instituições e fenômenos sociais, como é exemplo o futebol, terminam por atender ao senso comum e contribuindo para a permanência de estereótipos e silenciamentos.

Compreendemos que a mídia é uma das responsáveis pela (re)produção e concepção de subjetividades. Quando estudamos e categorizamos as notícias, em primeira instância, constatamos a nítida negligência da mídia para com o Mundial Feminino de Futebol. A pouca visibilidade dada a Marta e as demais jogadoras em detrimento ao amplo espaço dado aos atletas de mesma modalidade do gênero masculino. Bourdieu (2003) advogou que o campo jornalístico pertence ao campo político e, portanto, ambos sofrem influência do mercado. Se o mercado silencia e exclui determinados sujeitos, temas e modalidades, a mídia acompanha esse movimento. Basta relacionar e comparar a quantidade de matérias que são veiculadas durante a Copa do Mundo de Futebol Masculino com a as que são ligadas ao Mundial Feminino. Dessa forma, a produção e o consumo da informação caracterizam em muitos aspectos a distribuição do poder na sociedade (Sousa, 2006).

O futebol feminino, de forma geral, sofre cotidianamente pela falta de incentivo e investimentos das instituições no esporte. Essa deficiência, que acaba 
por influenciar diretamente no desempenho das atletas em campo, está relacionada a uma cultura sexista, principalmente no Brasil, que não dá o devido valor ao trabalho realizado pelas mulheres, seja em qualquer área, e esse fato só é reforçado num espaço masculinizado (Januário, 2015) como ainda é percebido o futebol. É notória a falta de apoio da mídia em disseminar o esporte, há poucos portais realizando a cobertura dos campeonatos de futebol feminino e os que falam não dão importância a dar voz a outras jogadoras, se não Marta. 0 preconceito parece iniciar dentro das próprias instituições que regulamentam o futebol. Não há respeito com os torneios oficiais, o presidente não aparece nas cerimônias, não há esforço para divulgação, deixam as meninas jogarem em gramado sintético, etc. Isso reflete no conteúdo que a mídia passa e consequentemente na falta de patrocínio. E ainda, apesar da visibilidade conferida à jogadora, parece existir uma necessidade de subterfúgios de comparação ao universo masculino acabam por diminuir a importância do seu trabalho, como se o esporte feminino fosse uma reprodução do masculino.

Marta é uma exceção, devido o desempenho pessoal e conquistas. Entretanto é notório que as poucas oportunidades de voz na mídia brasileira não conseguem, de forma isolada, mudar de forma efetiva a representação e a participação da mulher no esporte. Se faz necessário cobrar por mulheres na gestão esportiva, no campo tático e técnico. E ainda, por mais visibilidade de todo um quadro de atletas de alta performance no futebol nacional. De acordo com Cashmore (2000), as jogadoras de futebol nunca serão realmente levadas a sério enquanto o futebol for controlado exclusivamente por homens. Marta é um ícone indiscutível, que realmente merece toda a atenção midiática como atleta e jogadora, bem como a própria modalidade esportiva desempenhada por mulheres. É preciso uma mudança cultural para que de fato as mulheres recebam o incentivo necessário na profissão. Urge a necessidade de uma maior visibilidade da prática do esporte por mulheres na cobertura da mídia. A disseminação de um discurso mais equânime acerca da participação de homens e mulheres em um esporte que se configura como fenômeno social e popular, como o futebol, é também promover uma mudança na cultura e na sociedade. 


\section{REFERÊNCIAS}

BEAUVOIR, Simone. O segundo sexo. Rio de Janeiro: Nova Fronteira, 1980.

BOURDIEU, Pierre. Sobre televisão. Rio de Janeiro: Zahar, 1997.

BOURDIEU, Pierre. A distinção: crítica social do julgamento. Porto Alegre: Zouk, 2013.

BUTLER, Judith. Variações sobre sexo e gênero: Beauvoir, Witting e Foucault. In: BENHABIB, Seyla; CORNELL, Durscilla (orgs.). Feminismo como crítica da modernidade. Tradução de Nathanael da Costa Ceixeiro. Rio de Janeiro: Rosa dos Tempos, 1986, p. 139-154.

CASHMORE, Ellias. Making Sense of Sports. 3rd ed., London and New York: Routledge; 2000

ELIAS, Nobert. A sociedade dos indivíduos. Rio de Janeiro: Jorge Zahar Editora, 1994.

FADUL, Anamaria; REBOUÇAS, Edgar. Por uma perspectiva metodológica para os estudos dos sistemas e grupos de mídia: o caso do Nordeste brasileiro como referência. Anais do XXVIII Congresso Brasileiro de Ciências da Comunicação. Rio de Janeiro; São Paulo: INTERCOM, 2005. CD-ROM.

FOUCAULT, Michael. Microfísica do poder. Rio de Janeiro: Edições Graal, 1979.

GASTALDO, Edison. Uma arquibancada eletrônica: reflexões sobre futebol, mídia e sociabilidade no Brasil. Revista Antropologia Social. Paraná, vol. 6, 2005, p. 113-123.

GEERTZ, Clifford. As interpretações das culturas. Rio de Janeiro: Guanabara, 1989.

GOELLNER, Silvana. Bela, maternal e feminina: imagens da mulher na Revista Educação Physica. ljuí: Editora UNIJUÍ, 2003.

HALL, Stuart. A identidade cultural na Pós-Modernidade. Rio de Janeiro: DP\&A, 2005.

HELAL, Ronaldo. Mídia e esporte - A construção de narrativas de idolatria no futebol brasileiro. In: Anais do XXVI Congresso Brasileiro de Ciências da Comunicação. Minas Gerais; São Paulo, 2003, vol. 4, p. 19-36.

JANUÁRIO, Soraya Barreto. Modos de ver: a (in)visibilidade feminina enquanto profissional do esporte. XXXVIII Congresso Brasileiro de Ciências da Comunicação. São Paulo; Rio de Janeiro, 2015. Disponível em: https://goo.gl/GV4vkW. Acesso em: 10 set. 2015.

KELLNER, D. A. Cultura da mídia: estudos culturais - identidade e política entre o moderno e o pós-moderno. Bauru: EDUSC, 2001.

LANCENET. Grama sintética na Copa do Mundo feminina segue como alvo de críticas. Disponível em: https://goo.gl/K61PYq. Acesso em: 29 set. 2015. 
LOURO, Guacira L. Gênero, história e educação: construção e desconstrução. Educação \& Realidade, Porto Alegre, vol. 20, 1995, p. 99-108.

MAUSS, Marcel. Sociologia e antropologia. São Paulo: Cosac \& Naify, 2003.

OKIN, Susan. Gênero, o público e o privado. In: Revista Estudos Feministas, 2008, vol. 16, n. 2, p. 305-332.

SOUSA, Helena (org). Comunicação, economia e poder. Portugal: Porto Editora, 2006, p. 29-53.

STAKE. R. E. Case studies. In: DENZIN, N. K.; LINCOLN, Y. S. (ed.) Handbook of qualitative research. London: Sage, 2000, p. 435-454.

WINSHIP, Janice. Inside women's magazines. Londres: Pandora, 1987.

WITTER, João Sebastião. O que é futebol. São Paulo, Brasiliense, 1990.

WOLF, Mauro. Teorias da comunicação. Lisboa: Editorial Presença, 1995.

WOLF, Naomi. The beauty myth. Nova York: Harper Collins, 2009.

YIN, Robert. Estudo de caso: planejamento e métodos. 2. ed. São Paulo: Bookman, 2001. 